\title{
An assessment of a new breath actuated inhaler device in acutely wheezy children
}

\author{
N R Ruggins, A D Milner, A Swarbrick
}

\begin{abstract}
A randomised double blind, two period cross over study was designed to compare the ability of 51 hospitalised asthmatics with acute exacerbations to use each of two inhalers. The inhalers compared were a new breath actuated metered dose inhaler, the Autohaler inhalation device, and a dry powder device, the Rotahaler. Preassessment data included the measurement of peak inspiratory flow rate (PIFR), peak expiratory flow rate (PEFR), pulse rate, and oxygen saturation. Therapeutic response to each inhaler was compared by measurement of PEFR, oxygen saturation, and pulse rate.
\end{abstract}

PIFR was sufficient in all children to fire the Autohaler, including the youngest. No significant difference was found between the two inhalers as assessed by PEFR. However the Autohaler inhalation device could be actuated 99/100 times successfully compared with 74 for the Rotahaler. There was a consistent, but clinically insignificant, increase in pulse rate after use of the Rotahaler compared with the Autohaler. All 11 patients under 6 years of age failed to empty the Rotahaler but five of these patients received a significant benefit from using the Autohaler compared with after the Rotahaler.

A significant drop in oxygen saturation was observed 15 minutes after use of either inhaler. This may at times reach levels of clinical importance.

(Arch Dis Child 1993; 68: 477-480)

The emphasis of asthma treatment remains on the inhaled route where possible, ${ }^{1}$ so concentration on the development of effective delivery systems is justified. Much effort and research is directed into the design of inhalers that are more easily and reliably used for the treatment of asthma. The problems of good inhaler use are well illustrated by the asthmatic child and this is particularly so when they are acutely wheezy.

One of the major problems with the use of the press and breathe metered dose inhaler (MDI) is the need to coordinate actuation of the inhaler with inspiration. Previous studies have shown that about $30 \%$ of children are unable to do this. ${ }^{2}$ Spacers and dry powder devices have been introduced in an attempt to overcome this problem. However the spacer devices are bulky and not readily portable and some powder devices are slow to load and prime. The Autohaler (3M Riker) is a MDI that has been designed to overcome the problem of coordination by being breath actuated. Once primed the triggering mechanism responds to the movement of a vane that is rotated by a low inspiratory flow rate of approximately $30 \mathrm{l} / \mathrm{min}$.

The aim of this study was to compare the performance of the Autohaler and the Rotahaler (Allen and Hanburys) in acutely wheezy children. We felt this to be justified in judging the response to bronchodilator administered by these devices in the true clinical situation, rather than by provoking wheeze and then monitoring the response. The Rotahaler was used as it is familiar and has been used by the majority of asthmatic patients at one time or another. By looking at the content of the Rotacap after use of the device we could also have a measure of the effectiveness with which the powder had been inhaled.

\section{Subjects and methods}

Asthmatic children were enrolled into the study during a hospital admission for treatment of an acute exacerbation. Entry criteria required were: a previously documented history of asthma, absence of lower respiratory tract infection, and a need for treatment with regular nebulised salbutamol. Subjects were studied twice on the study day at least two hours after their last nebulised treatment. Medication taken before admission and on the day of study was recorded.

Prestudy assessments involved recording the age, weight, and height of all subjects. Pulse rate and oxygen saturation were measured using an Ohmeda Biox 3700 pulse oximeter with a finger probe once a satisfactory signal was obtained. All the equipment was mounted onto a trolley so that assessments could be performed at the bedside and the subjects were able to see the chart recorder in order to encourage them to perform at their best. Peak inspiratory flow rate (PIFR) was then measured using a mercury pneumotachograph and a mouthpiece of similar diameter to the inhalers studied, and recordings were printed out on a single channel chart recorder. Peak expiratory flow rate (PEFR) was similarly measured. The pneumotachograph was subsequently calibrated using known flow rates with a rotameter and generating a calibration curve. Each measurement was repeated three times and all results were recorded but only the best achieved used for analysis.

This was a double blind, double dummy, cross over study. Patients were randomised to receive in the first period one study inhaler containing active salbutamol and the other placebo. In the second study period the inhaler containing the active drug was reversed. The inhalers compared were the Autohaler at $100 \mu \mathrm{g}$ per actuation and the Rotahaler loaded with a $\mathbf{4 0 0 \mu}$ g Rotacap. Before each study the subject was familiarised 
with the inhaler techniques required and practised with a placebo inhaler. At each study period the subject was allowed two attempts to fire the Autohaler, a maximum possible dose of $200 \mu \mathrm{g}$ salbutamol, or two inhalations from the Rotahaler loaded with the single Rotacap, a maximum possible dose of $400 \mu \mathrm{g}$. Inhaler technique was considered satisfactory if the Autohaler was fired and the Rotahaler emptied. This assessment was made by the respiratory nurse and blind to the investigator making the measurements.

Response to treatment was measured by recording heart rate, oxygen saturation, and PEFR at 5, 15, and 30 minutes after administration of the study inhalers. Any adverse events were recorded.

Written informed consent was obtained from the subjects' parents and the study was approved by the local ethical committee.

Statistical analysis was carried out on the 51 randomised patients. All tests were two sided and carried out at the $5 \%$ significance level. A test for carryover effect within the Grizzle approach was carried out at the $10 \%$ level to confirm the validity of using the data from the second study period.

\section{Results}

Fifty one asthmatics were studied, 33 boys (65\%) and 18 girls, median age 9 years (4-13 years). Eleven patients were under 6 years of age. All except two patients completed both study periods, one refusing to cooperate in the second study period and the other having been discharged home before completing the study. Twenty five patients were randomised to receive the active Autohaler in the first study period and 26 the active Rotahaler.

Before admission 25 patients were taking regular inhaled steroids (49\%) and eight had already commenced on oral prednisolone. On the study day, apart from the requirement of regular nebulised salbutamol, $45(88 \%)$ were on oral prednisolone and four $(8 \%)$ on intravenous hydrocortisone. Five $(9 \cdot 8 \%)$ were treated with intravenous aminophylline infusions. The treatment regimens were not altered between the two study periods.

\section{PIFR}

Mean (SD) PIFR was 109.5 (45) $1 /$ min recorded in the first study period and 113.5 (44) $1 / \mathrm{min}$ in the second, a clinically insignificant difference. There was a significant positive correlation between PIFR and PEFR (Pearson's correlation coefficient $0.55, p<0.001$ ). Figure 1 shows the PIFR measured in the wheezy children of different ages. As can be seen, the lowest PIFR recorded was $30 \mathrm{l} / \mathrm{min}$ and most patients could generate a PIFR sufficient to trigger the opening mechanism of the Autohaler, including the youngest in the study.

\section{ABILITY TO USE INHALER}

There was one failure in 100 actuations $(1 \%)$ of the Autohaler as compared with $26 / 100(26 \%)$

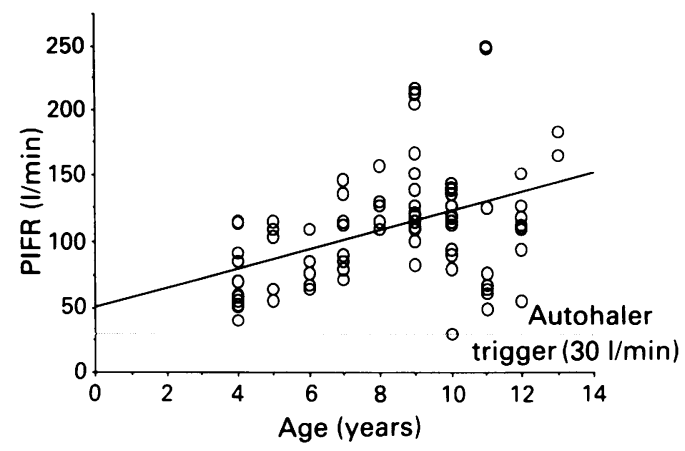

Figure 1 Relation between PIFR (l/min) and age of wheezy child.

unsuccessful attempts to empty the Rotacap after two inhalations. The patient who failed to fire the Autohaler was 4 years old with a PIFR of $60 \mathrm{l} / \mathrm{min}$ and also failed to empty the Rotacap. Twenty patients failed to empty the Rotacap on at least one occasion. This number included all 11 of the children aged less than 6 years of age.

\section{PULSE RATE}

A significant and consistent increase in pulse rate was recorded after the use of the Rotahaler as compared with the Autohaler. This was true at $5(p=0.05), 15(p=0.04)$, and 30 minutes $(\mathrm{p}<0.001)$, with the maximum increase after dosing being 5.8 beats/minute (adjusted mean) with the Autohaler compared with 9.4 for the Rotahaler (adjusted mean difference -3.5 $\mathrm{p}<0.01)$. It also took significantly longer to reach maximum heart rate after dosing with the Rotahaler $(14.8 \mathrm{~min})$ compared with the Autohaler $(10 \cdot 3 \mathrm{~min} ; \mathrm{p}=0.02)$.

\section{OXYGEN SATURATION}

A total of $47 \%$ of baseline oxygen saturation recordings indicated a mild degree of hypoxia $(<95 \%)$. Only one patient had an oxygen saturation of $<90 \%$ on entry into the study, but after use of the test inhaler 11 patients dropped below $90 \%$. The maximum recorded drop in saturation recorded was of $8 \%$ after use of the inhaler. There was a statistically significant drop in oxygen saturation five minutes after treatment (Student's $t$ test $\mathrm{p}<0.01$ ), the maximal effect being seen at 15 minutes $(p<0.01)$. By 30 minutes oxygen saturation had improved but had not quite reached pretreatment values $(p<0.05)$. Figure 2 shows the change in oxygen saturation after the use of the two inhalers when looked at separately, and shows no significant difference in the observed desaturation between the two inhalers at 15 minutes. There was no significant difference between pretreatment saturation and that at 30 minutes after use of the Autohaler $(p=0.38)$ but there was a difference after use of the Rotahaler $(p<0 \cdot 05)$.

PEFR

Overall there was no evidence of a statistically significant difference between the inhalers with respect to PEFR. Figure 3 shows the maximum improvement in PEFR after the use of each inhaler. The maximum increase in PEFR with 


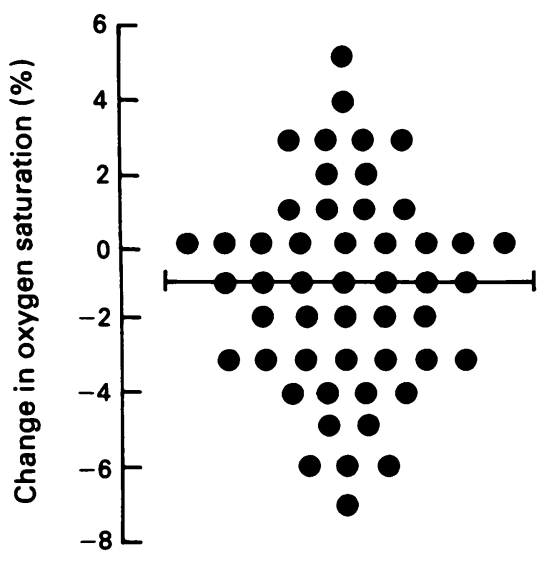

Autohaler

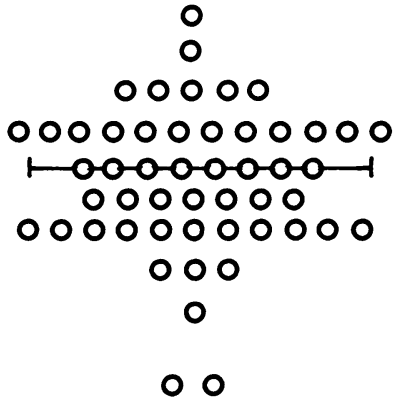

Rotahaler
Figure 2 Change in oxygen saturation from baseline 15 minutes after use of each inhaler.

the Autohaler had a mean value of $44.7 \mathrm{l} / \mathrm{min}$ compared with $45 \cdot 1 \mathrm{l} / \mathrm{min}$ with the Rotahaler $(p=0.94)$. There was also no significant difference in the time required to achieve that peak value $(\mathrm{p}=0.34)$.

Eleven $(21.6 \%)$ patients showed a worthwhile improvement (increase in PEFR $>30 \mathrm{l} / \mathrm{min}$ ) after use of the Autohaler who failed to improve after the Rotahaler. Five of these subjects were aged under 6 years. Six of these 11 patients were unable to empty the Rotahaler whereas the remaining five could use the Rotahaler successfully but failed to show a significant improvement in PEFR.

Nine patients who showed improvement with the Rotahaler failed to improve their PEFR after successful activation of the Autohaler (table).

\section{ADVERSE EVENTS}

There were no reported adverse events after administration of the study inhalers.

\section{Discussion}

Unlike other studies assessing PIFR in children, our results in acute attacks showed that most patients enrolled had relatively high inspiratory flows. However the correlation between PIFR and PEFR has been described previously in well children and appeared to still hold in the acutely wheezy, ${ }^{3}$ indicating that the asthma attack is reducing inspiratory as well as expiratory

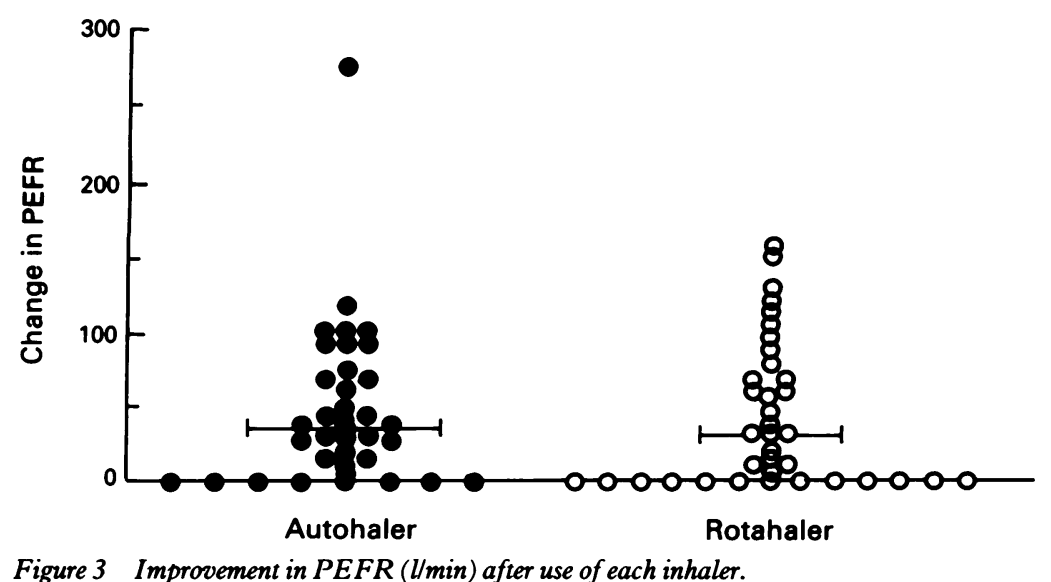

flow rates. Most of the children studied could generate a PIFR sufficient to trigger the Autohaler when acutely wheezy.

The Autohaler could be actuated reliably by these wheezy children (99\%) whereas often they were unable to empty a Rotacap (26\%). However when looking at response in terms of improvement in PEFR there was no difference between the two inhalers studied. Only relatively small doses of salbutamol administered by these devices were studied, $200 \mu \mathrm{g}$ in the case of the Autohaler and $400 \mu \mathrm{g}$ Rotacaps, whereas the patients would be receiving $2.5 \mathrm{mg}$ or $5 \mathrm{mg}$ from the nebuliser. So it is not surprising that the improvements seen with the study inhalers are small and that some patients fail to improve with the dosage used.

The group of patients who failed to improve with the Autohaler but improved after use of the Rotahaler in the other limb of the study are shown in the table. Of these nine patients five had recorded PEFR of greater than $90 \%$ of expected based on their height and so would not have been expected to show further significant bronchodilation. A further patient had a low PIFR of only $30 \mathrm{l} / \mathrm{min}$ and although able to actuate the inhaler, was unable to demonstrate any benefit from its use. It is probable that although the three remaining patients activated the Autohaler the drug had failed to reach the lower respiratory tract. There have been concerns about glottic closure after the firing of the Autohaler limiting the subsequent dose delivered to the lungs. Overall, our findings suggest that the Autohaler works at least as well as the Rotahaler, whether or not glottic closure is a problem. Naturally when teaching children to use the Autohaler we should emphasise that continuing to breathe in to full inspiration once the Autohaler has fired is important to get the maximum benefit.

One particular group worth highlighting are those aged under 6 years. This group is difficult to treat reliably with inhalers and all 11 of these patients in this study failed to either improve after use of the Rotahaler or empty the Rotacap. Ten of these children did however manage to actuate the Autohaler and $50 \%$ of these showed some improvement in PEFR. This group were selected to a certain degree in that they needed to be able to perform the measurements of PIFR and PEFR. However the use of the Autohaler in this young age group may be worthy of further study.

The higher pulse rate response recorded consistently after the use of the Rotahaler is an interesting observation rather than of any clinical relevence. It may be explained by the fact that the Rotacap contained double the dose administered by the MDI, although most would agree these were of equivalent effective doses. This effect could be explained by increased oral absorption of the powder from the Rotahaler. This is supported by the finding that the peak in pulse rate was delayed compared with that observed after the Autohaler, suggesting it may originate from systemic absorption rather than from the inhaled route.

Similarly interesting observations are made in the oxygen saturation recordings after dosing. 
Details of patients who failed to improve after use of the Autohaler

\begin{tabular}{lccc}
\hline Age (years) & $P I F R\left(L_{\min }\right)$ & $P E F R\left(L_{\min }\right)$ & $\begin{array}{l}\% \text { Predicted } \\
P E F R\end{array}$ \\
\hline 10 & 30 & 158 & 56 \\
11 & 120 & 130 & 45 \\
10 & 120 & 150 & 48 \\
10 & 136 & 430 & $>100$ \\
10 & 128 & 284 & $>100$ \\
13 & 184 & 422 & $>100$ \\
4 & 56 & 92 & 88 \\
9 & 205 & 328 & $>100$ \\
7 & 112 & 221 & 98 \\
\hline
\end{tabular}

Such changes have been reported previously after nebulised salbutamol in children with asthma. Oxygen saturation was significantly lower at 5 and 15 minutes after treatment, returning to preinhalation levels at $\mathbf{3 0}$ minutes, similar to the findings of others. ${ }^{4}$ This effect is thought to be due to a change in ventilation: perfusion ratio with a relatively greater increase in perfusion than in ventilation. ${ }^{5}$ Our results show that this occurs with salbutamol inhaled via a MDI or a Rotahaler as well as that previously reported with nebulised salbutamol. The desaturation recorded does not often reach clinical significance but could be important in a child who is tending to overuse an inhaler in an attempt to relieve wheezing. The maximum $8 \%$ drop in saturation recorded could result in significant deterioration in a child who may already be mildly hypoxic. Some patients who showed desaturation failed to show improvement in PEFR after use of the inhaler. The same significant trends were seen with both the Autohaler and Rotahaler, the only difference being that after the use of the Rotahaler, unlike the Autohaler, the pretreatment saturation had still not been attained by the end of the study period of 30 minutes.

The Autohaler performed as well as the Rotahaler in terms of PEFR response and more children were able to activate it consistently. Those under 6 years of age, when wheezy, were particularly bad at using the Rotahaler but some of these showed a worthwhile response to the Autohaler. There may be some theoretical advantages in terms of our observations of effect on pulse rate and oxygen saturation although these are unlikely to be of any clinical significance. Although PIFR measurement may be a useful indicator, it is clear that the generation of enough inspiratory flow is not the only prerequisite for good inhaler use. Similarly coordination is not the only problem that needs to be tackled in the development of new delivery systems. We must continue to tailor the device to the particular requirements of our patients and ensure their ability to use such devices reliably and effectively. The Autohaler is one such device that may be well suited to some of our asthmatic patients.

1 Warner JO, Gotz M, Landau LI, et al. Management of asthma: a consensus statement. Arch Dis Child 1989; 64: 1065-79.

2 Mortensen S, Pederson S. Use of a new breath actuated inhaler in children. The Medicine Publishing Foundation Symposium Series, 1988; 26: 7-12.

3 Pederson S, Hanson OR, Fugslang G. Influence of inspiratory flow rate upon the effect of a Turbohaler. Arch Dis Child 1990; 65: 308-19.

4 Gleeson JGA, Green S, Price JF. Air or oxygen as driving gas for nebulised salbutamol. Arch Dis Child 1988; 63: 900-4.

5 Tal A, Pasterkamp H, Leahy F. Arterial oxygen desaturation following salbutamol inhalation in acute asthma. Chest 1984; 86: 868-9. 